\title{
Bidirectionality of language contact: Spanish and Catalan vowels
}

\author{
Annie Helms*
}

\begin{abstract}
The disproportionate number of studies in Barcelona and the Balearic Islands observing Spanish contact effects in Catalan production, rather than Catalan contact effects in Spanish production, is an oversight of bidirectionality and the probabilistic nature of social factors in situations of language contact. Accordingly, the present study analyzes both Catalan and Spanish mid front vowel production data from Barcelona to investigate whether Catalan contact effects occur in Spanish via a process of dissimilation, and whether such effects are strengthened in younger speakers due to the relatively recent implementation of Catalan linguistic policy in the educational and public spheres. The results are suggestive of dissimilation, where phonetic distinctions are maintained between Spanish /e/ and the two Catalan mid front vowels across both F1 and F2. Additionally, analyses of variance across F1 and F2 reveal that Spanish /e/ productions across F1 are more diffuse in younger speakers and Catalan mid front vowels across F2 are less diffuse, providing evidence of reciprocity in contact effects. These results underscore the bidirectional nature of language contact and advocate for the use of variance of F1 and F2 as a metric of phonological contact effects.
\end{abstract}

Keywords. language contact; Spanish; Catalan; vowels; phonetic variation; bilingualism

1. Introduction. Language contact is often discussed as 'Language A' in contact with 'Language B', which overlooks the conduit by which this contact occurs - the bilingual individual. The literature on individual bilingualism and its phonological outcomes is extensive, and evidence for bidirectional, or reciprocal, influence between the L1 and L2 is abundant. However, the analogous literature at the level of the speech community is not as readily apparent, yielding a discussion of contact effects in the speech community that is biased towards unidirectional effects, especially in the case of Spanish and Catalan in Catalonia (see also Davidson 2020; Galindo i Solé 2003). Using the bidirectional nature of L1-L2 influence in the phonological repertoire of the individual as a foundation for the analysis of contact effects in a community, a broader methodological scope is required to more accurately assess contact effects in a community with long term bilingualism as the norm.

1.1. Bidirectionality of Language COntaCt. Grosjean (1989) famously asserts that a bilingual is not two monolinguals in one, but that the two languages co-exist and interact. Weinreich (1968) similarly refutes the monolingual perspective on bilingualism, defining bilingual interference as "instances of deviations from the norms of either language which occur in the speech of bilinguals" (emphasis added, Weinreich 1968; p. 1), indicating that effects of contact between the L1 and L2 are bidirectional. The possible influence of the L2 on the L1 is acknowledged in the literature (Cook 2003; Grosjean 1989; Weinreich 1968; Birdsong 2018), but evidence is not as readily available (Cook 1999). Notable evidence of L2 influence on the

\footnotetext{
* I would like to thank Justin Davidson and Ernesto Gutiérrez Topete (UC Berkeley) and my audience at the 2021 LSA Annual Meeting for their feedback on aspects of this research at various stages, and Antonio Torres Torres (Universitat de Barcelona) for his support in data collection. Author: Annie Helms, University of California, Berkeley (annie_helms@berkeley.edu).
} 
L1, however, includes convergence of VOT in the L1 and L2 among French-English (Flege 1987) and Italian-English bilinguals (MacKay et al. 2001). Specific processes by which phonological categories from the L1 and L2 may interact, yielding deviations from the monolingual norms of either category, include assimilation and dissimilation (Flege 1995, 2002, 2007). If an L2 vowel category is perceived to be equivalent to an L1 vowel category, despite aurally detectable differences, the formation of a new category will be blocked. Blockage of category formation results in perceptual assimilation, by which the speaker may produce a composite L1-L2 vowel category (Evans \& Iverson 2007; Kendall \& Fridland 2012). The quality and quantity of input the bilingual receives in their lifetime, among other factors, will determine whether the composite category more closely maintains properties of the L1 or the L2 vowel category (Flege 2002; Yeni-Komshian et al. 2000). Alternatively, dissimilation is the process whereby L1 and L2 categories are perceived as different and phonological distinction between the two is maintained, even if the categories are not produced in a native-like manner (Baker \& Trofimovich 2005). Having developed an individual-level view of bidirectional contact between the L1 and L2, it is now necessary to examine broader factors which probabilistically condition directionality at the community level.

In a situation of language contact between a majority language and a minority language, where one language is privileged in social, legal, political, and educational affairs, the social factors are more likely to favor contact effects from the majority language to the minority language. Thomason (2010) and Thomason \& Kaufman (1988) further elaborate the social factors that may probabilistically influence the directionality of contact effects, including speaker attitudes, intensity of contact, and availability of monolingual-like exemplars. The important aspect to note is that these factors offer probabilistic constraints on directionality of contact effects; majority language agentivity may be favored and contact effects may be asymmetrical, but the probability of minority language agentivity need not be zero. In other words, evidence of reciprocity and bidirectionality in contact situations should be expected, even if contact effects from one language are more prevalent. Therefore, as Davidson (2020; p. 18) demonstrates, "unique social contexts serve to probabilistically favor distinct linguistic outcomes," underscoring the importance of the social context, as well as the methodology employed to observe contact effects.

\subsection{Bilingualism in Barcelona. In Barcelona, Spanish and Catalan have been in close} contact for centuries and many instances of lexical and phonological imposition and borrowing have been recorded (e.g. Galindo i Solé 2003, 2006; Arnal 2011). The public use of Catalan has been repeatedly threatened by legislation, such as the Nueva Planta decrees (17071716) and linguistic policies during Franco's dictatorship (1939-1975), but saw unprecedented growth and protection under the Catalonian Linguistic Normalization Law (1983). This law decreed Castilian Spanish and Catalan to be co-official in the region, and that all public education be carried out in Catalan. The timing of the implementation of this law has yielded a generational divide in Catalonia between those that have and have not had access to prescriptive Catalan norms through schooling, highlighting the importance of including age as a factor in production studies in Barcelona. The impact of these linguistic policies can be observed in data from 1986 to 2011 regarding knowledge of Catalan in Barcelona. According to the Institut d'Estadística de Catalunya, 95.4\% of residents reported they could understand Catalan in 2011, whereas $92.9 \%$ reported similarly in 1986. In 2011, $72.3 \%$ could speak Catalan, up 
from $67.4 \%$ in 1986 . Lastly, $79.2 \%$ of residents in 2011 could read Catalan and $53.1 \%$ could write in Catalan, whereas the percentages were respectively $66.8 \%$ and $33.5 \%$ of residents in 1986 (Idescat 2011). From these data, it appears that the educational reforms established in 1983 with the Catalonian Linguistic Normalization Law are mainly reflected in the increased prevalence of the ability to read and write in Catalan.

Due to the globalization of the city and the influx of immigration, Barcelona has the lowest percentage of L1-Catalan speakers within Catalonia (Lleó et al. 2008; p. 186). Regardless, Catalan remains an important aspect of Barcelona culture, though more recently in the context of linguistic cosmopolitanism and bilingual identity rather than in ideologies of monolingual purism (Newman \& Trenchs-Parera 2015). Despite the vitality of Catalan and the social and linguistic capital afforded to the language, there is a decided bias in the literature towards Spanish contact effects in Catalan (see Arnal 2011). Spanish and Catalan mid back and mid front vowels, in particular, are the focus of many such studies, as the production of the Catalan categories offers opportunity for study of the effects of age of acquisition, language dominance, exposure and language ideology on the presence or absence of Spanish contact effects in Catalan.

1.3. Spanish and Catalan vowels in COntact. Whereas Spanish has one mid front vowel and one mid back vowel, /e/ and /o/, Catalan has two contrasting mid front vowels and two contrasting mid back vowels (e.g. /net/ 'grandson' and /net/ 'clean'; /os/ 'bear' and /os/ 'bone'). Regarding the mid front vowels, with which this study is concerned, Spanish /e/ is produced lower (higher F1) than the Catalan /e/, but higher (lower F1) and more fronted (higher F2) than the Catalan / $\varepsilon /$ (Figure 1). However, production studies have indicated that the most significant sources of variability among the three vowel categories are found across F1, not F2 (Bosch \& Ramon-Casas 2011; Cortés et al. 2009; Recasens \& Espinosa 2006; Simonet 2011). The social and linguistic factors observed to influence the degree of maintenance or weakening of the Catalan contrasts in Barcelona and Mallorca include language exposure (Cortés et al. 2019; Bosch \& Ramon-Casas 2011), daily language usage (Cortés et al. 2019; Mora \& Nadeu 2012), language dominance (Amengual 2016; Pallier et al. 1997; Simonet 2011), and Spanish cognate status (Mora \& Nadeu 2012). Though these factors have been examined as probabilistic weights affecting the presence of Spanish contact effects in Catalan, they can also be analyzed in terms of Catalan contact effects in Spanish. In a perception study, Pallier et al. (1997) found that more Catalan-dominant bilinguals assimilated their Spanish /e/ towards their Catalan
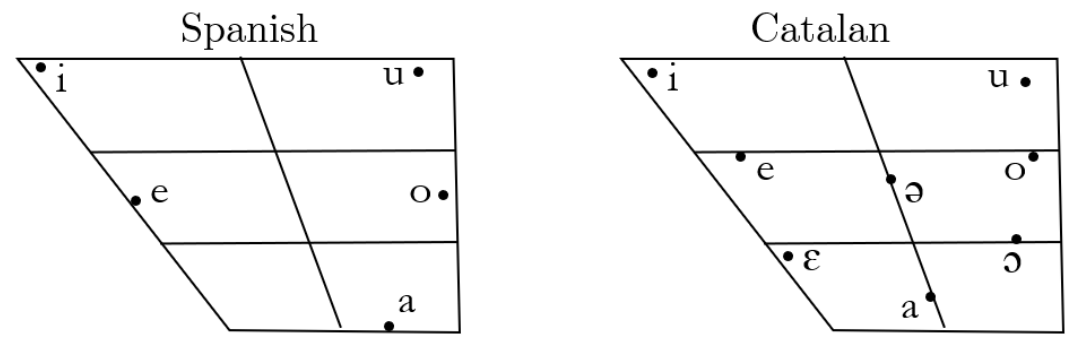

Figure 1. Vowel Spaces of Spanish (Ladefoged \& Johnson 2015; p. 237) and Catalan (Carbonell \& Llisterri 1999; p. 62) 
/e/, evidencing contact effects from Catalan. In an analysis of the production of Spanish and Catalan back mid vowels in Mallorca, Simonet (2011) used Catalan cognate status as a potential factor to observe variable Spanish /o/ production. Though no cognate effect was found in Spanish, both Spanish-dominant and Catalan-dominant bilinguals produced a Spanish /o/ that was distinct from their productions of either Catalan back-mid vowel. Thus, bilingual speakers in this community received sufficient input from and exposure to both Spanish and Catalan exemplars that they were able to maintain an acoustic distinction cross-linguistically via dissimilation, even if monolingual-like targets were not attained.

1.4. The PRESENT STUDY. As the influence between Spanish and Catalan is not deterministically unidirectional, but rather is constrained probabilistically by a myriad of social and linguistic factors, it is necessary to approach an acoustic investigation of Spanish and Catalan vowels with a methodology that allows for the possibility of both Spanish contact effects and Catalan contact effects to be observed. Though Catalan is considered a minority language, the social and political prestige afforded to Catalan in Barcelona, as well as the widespread societal bilingualism and instruction of Catalan, may make Catalan contact effects in Spanish probable, alongside Spanish contact effects in Catalan. Accordingly, to observe bidirectional contact effects, productions of mid front vowels from both languages are analyzed. Additionally, with the increased exposure to Catalan in the educational, social, and political spheres due to the Linguistic Normalization Law of 1983, Catalan contact effects may be more favorable among speakers of the younger generation. Therefore, I hypothesize:

- Bilinguals will produce Spanish /e/ distinctly from the two Catalan mid front vowels via a process of dissimilation, regardless of any potential mergers in Catalan, demonstrating Catalan and/or Spanish contact effects.

- Catalan contact effects will be more robust in the production of younger speakers than in the production of older speakers.

The observation of dissimilation will be operationalized by an acoustic analysis (F1 x F2) of Spanish and Catalan mid front vowels across language, vowel, and age. An analysis of variance (F1 x F2) in each language and in each age group be will performed as a methodological response to broaden the use of metrics to those where contact effects from both languages may be observed.

2. Methodology. Data collection occurred in 2019 and seventeen participants were recruited with flyers posted at the University of Barcelona, stratified by age and gender. Participants were categorized into two generations, one group between 18-25 years old, and one group between 40-65 years old. This generational gap is used to comment on language change in apparent-time, where younger speakers are presumed to lead the community-wide adoption of new variants (Labov 2001; Tagliamonte 2012). Additionally, the group of older speakers was not formally educated in Catalan, whereas the younger group did benefit from this education under the Catalonian Linguistic Normalization law of 1983. All participants self-identified as bilingual in Spanish and Catalan and were residents of Barcelona for at least 10 years prior to data collection. Each participant completed the Bilingual Language Profile (Birdsong et al. 2012) and was subsequently assigned a Catalan-Spanish dominance score (minimum: -218; maximum: +218), where a more positive dominance score is correlated with greater Catalandominance and a more negative dominance score is correlated with greater Spanish-dominance. 


\begin{tabular}{lccc} 
Age Group & Mean dominance score & Std. Dev. & Count \\
\hline Older (40+ years) & +69.29 & 59.77 & 7 \\
Younger (18-25 years) & +33.79 & 41.20 & 10 \\
\hline
\end{tabular}

Table 1. Catalan-Spanish dominance scores across age groups.

All but four participants were more Catalan-dominant, and the mean dominance and standard deviations across age are shown in Table 1. At the time of data collection, all participants were connected to the University, or had been connected in the past. No participant reported any history of speech or hearing disorders.

The experiment consisted of two elicited production tasks, one in Spanish and one in Catalan. The Spanish word list used in the elicited production task was stratified according to cognate status, where 40 words have Catalan cognates and 20 words do not. The Spanish words with Catalan cognates were further stratified according to the Catalan vowel found in the cognate (either /e/ or $/ \varepsilon /$ ). An online dictionary with transcriptions of the Barcelona variety of Catalan (Alcover \& Moll 2002) was used to determine the vowel prescriptively present in each Catalan cognate. The Catalan word list consisted only of the 40 Catalan cognates. According to the online corpus NIM (Guasch et al. 2013), all words from the Spanish word list have a relative frequency of at least 10 parts per million (ppm), and all words from the Catalan word list have a relative frequency of at least $5 \mathrm{ppm}$. In both word lists, all vowel segments under analysis occur in stressed syllables. Additionally, Spanish words where /e/ is followed by a palatal sound, like $/ \mathrm{j} /$, or either an $/ \mathrm{x} /$ or an $/ \mathrm{r} /$, were excluded, as the former lowers the $\mathrm{F} 1$ of /e/ production and the latter phones raise the F1 of /e/ (Hualde 2013; p. 115). Before data collection began in Barcelona, a pilot study was implemented with the participation of four trained linguists who are native speakers of Catalan and/or Spanish. After the experiment, none of the participants were able to identify the sound of interest, so to reduce the duration of the experiment, neither word list included filler tokens. Each word list was randomized and all participants saw the same order of words. All recording sessions took place in an empty classroom at the University of Barcelona. First, the participants were instructed to read and sign the consent form and complete the Bilingual Language Profile, adapted as a Qualtrics survey (Qualtrics 2005). Next, the researcher conducted sociolinguistic interviews with each participant (data not analyzed in the present study), and finally presented them with the Spanish word list. The production of these token stimuli was recorded using a Zoom H4N Multitrack Recorder and Comica Lavalier microphone. After the Spanish word list, participants were additionally asked to read aloud from the Catalan word list and were recorded.

2.1. AnAlysis. The 680 Spanish productions with Catalan cognates and all 680 Catalan mid front vowels productions were submitted to statistical analysis, for a total of 1,360 vowels. For the Spanish data, time-aligned, word- and phoneme-segmented TextGrid files were generated using Montreal Forced Aligner (McAuliffe et al. 2017). The TextGrids were hand-corrected in Praat (Boersma \& Weenink 2019), and a Praat script (Riebold 2013) was used to extract measurements for F1, F2, and F3 at the midpoint of each stressed /e/ phone marked in the TextGrid, in order to minimize co-articulation effects upon the formant measurements. The same procedure was carried out for the Catalan mid front vowels, and vowel categories were classified following the target vowels in the word list. The F1 and F2 measurements for all 
Spanish and Catalan mid front vowels were normalized across vocal tract length, using the Lammert and Narayanan $\Delta \mathrm{F}$ normalization method (Johnson 2020), which can be calculated using only a subset of vowels from the acoustic space. To observe potential evidence of dissimilation between the two languages, F1 and F2 data were submitted to separate mixed effects linear regression models, with three-way interactions of AGE (Younger or Older), LANGUAGE (Spanish or Catalan), and VOWEL (/e/ or $/ \varepsilon /$ ), and random intercepts of PARTICIPANT and TOKEN WORD. Following Simonet (2011), VOWEL corresponded to the vowel quality of Catalan and Spanish productions. The target vowel in the Catalan word was used to make this assignment for Catalan productions. However, given that Spanish only has one mid front vowel, /e/, Spanish productions were categorized on the basis of the target vowel in the Catalan cognate. For example, the Spanish mid front vowel produced in método 'method' was classified as ' $/ \varepsilon /$ ' because the Catalan cognate mètode contains the target vowel $/ \varepsilon /$. In addition to regression models predicting $\mathrm{F} 1$ and $\mathrm{F} 2$, calculations of variance equivalence across $\mathrm{F} 1$ and $\mathrm{F} 2$ were performed (Amengual 2011) using Levene's test, with a two-way interaction of AGE and LANGUAGE. As pre-analysis of the data corroborates previous findings in Barcelona (e.g. Mora $\&$ Nadeu 2012) and indicates mergers or near mergers of the Catalan front mid vowels across all participants, the Catalan /e/ and / $/$ / productions were grouped in this analysis as a single merged category. Tests of variance can characterize the diffuseness of vowel categories across formant axes and how social factors may mediate this diffuseness, essentially describing the range of acceptable exemplars for that category.

3. Results. The regression coefficients (Table 2) for the mixed effects linear regression model predicting F1 across AGE, VOWEL, and LANGUAGE indicate significant main effects of LANGUAGE $(p<0.01)$, VOWEL $(p<0.01)$, and significant effects of the interaction between LANGUAGE and VOWEL $(p<0.01)$ and of the interaction between AGE and VOWEL $(p<0.01)$. Recall that for Catalan productions, VOWEL refers to the target vowel in the Catalan word, and for Spanish productions, vOWEL refers to the vowel in the Catalan cognate. Subsequent Tukey post-hoc tests of the interaction between LANGUAGE and VOWEL reveal that these bilingual speakers maintain phonetic contrasts between Catalan /e/ and Spanish /e/ $(\beta=0.07830, p<$ $0.01)$ and between Catalan $/ \varepsilon /$ and Spanish ' $/ \varepsilon /$ ' $(\beta=0.01730, p<0.01)$. Therefore, across F1, Spanish productions are significantly different from both Catalan mid front vowel categories, where the Spanish productions are lower than the Catalan /e/ productions, but higher than the

\begin{tabular}{lccccc} 
& Estimate & Std. Error & $t$-value & $p$-value & \\
\hline (Intercept) & $5.099 \mathrm{e}-01$ & $1.857 \mathrm{e}-02$ & 27.452 & $2 \mathrm{e}-16$ & $* * *$ \\
Spanish & $-8.435 \mathrm{e}-02$ & $6.213 \mathrm{e}-03$ & -13.577 & $2 \mathrm{e}-16$ & $* * *$ \\
Younger & $3.390 \mathrm{e}-02$ & $2.303 \mathrm{e}-02$ & 1.472 & 0.158 & \\
le/ & $-7.849 \mathrm{e}-02$ & $1.023 \mathrm{e}-02$ & -7.673 & $4.01 \mathrm{e}-11$ & $* * *$ \\
Spanish: Younger & $1.211 \mathrm{e}-02$ & $8.100 \mathrm{e}-03$ & 1.495 & 0.135 & \\
Spanish: /e/ & $6.895 \mathrm{e}-02$ & $8.786 \mathrm{e}-03$ & 7.847 & $8.80 \mathrm{e}-15$ & $* * *$ \\
Younger: /e/ & $3.341 \mathrm{e}-02$ & $8.100 \mathrm{e}-03$ & 4.124 & $3.96 \mathrm{e}-05$ & $* * *$ \\
Spanish: Younger: /e/ & $-1.590 \mathrm{e}-02$ & $1.146 \mathrm{e}-02$ & -1.388 & 0.165 & \\
\hline
\end{tabular}

Table 2. Coefficients for the mixed effects linear regression model predicting F1. The intercept is the Catalan $/ \varepsilon /$ productions by older speakers. 
Catalan $/ \varepsilon /$ productions. Additionally, due to the differences in beta coefficients, Spanish /e/ is phonetically closer to Catalan /e/ than to Catalan $/ \varepsilon /$. As the difference in production between Spanish /e/ and Spanish '/ $/$ /' was not significant, there is no cognate effect in Spanish production. Even averaged across the levels of LANGUAGE, the older speakers showed a significant difference in productions of /e/ versus $/ \varepsilon /(\beta=0.0440, p<0.01)$, whereas the younger speakers did not. As this difference in Spanish was not significant, this result is suggestive of the weakening of the Catalan mid front vowel contrast in apparent-time.

Regarding the cross-linguistic productions across the F2 dimension, a similar mixed effects linear regression model was generated with a three-way interaction of AGE, LANGUAGE, and VOWEL. The regression coefficients (Table 3) for this model indicate significant main effects of LANGUAGE $(p<0.01)$, VOWEL $(p<0.01)$, and significant effects of the interaction between LANGUAGE and AGE $(p<0.01)$ and of the interaction between LANGUAGE and VOWEL $(p<$ 0.01). Subsequent Tukey post-hoc tests of the interaction between LANGUAGE and VOWEL reveal that these bilingual speakers maintain phonetic contrasts between Catalan /e/ and Spanish /e/ $(\beta=-0.0349, p<0.01)$ and between Catalan $/ \varepsilon /$ and Spanish '/ $/ \varepsilon$ ' $(\beta=-0.0934, p<0.01)$. Therefore, across F2, Spanish productions are significantly different from both Catalan mid front vowel categories. In this case, however, Spanish productions are not phonetically situated between the Catalan productions, but are more fronted than both Catalan categories. As in the model of F1 productions, the difference between Spanish /e/ and Spanish '/ع/' was not significant, meaning that no Catalan cognate effects were observed in Spanish. Tukey post-hoc tests of the interaction between LANGUAGE and AGE reveal that both older speakers and younger speakers had more fronted Spanish productions than Catalan productions, though the phonetic difference is about twice as large among the older speakers than the younger speakers (older speakers: $\beta=-0.08651, p<0.01$; younger speakers: $\beta=-0.04178, p<0.01)$. This suggests that the phonetic contrast between Spanish and Catalan mid front vowels across F2 is perhaps weakening in apparent-time. Productions across age, language, and vowel are visualized in Figure 2.

The lack of significance of the three-way interaction between VOWEL, LANGUAGE, and AGE indicates that both generations of speakers produce a Spanish /e/ that is phonetically distinct from either Catalan vowel across F1 and F2. However, formant frequencies are not the only metric that can be used to compare cross-linguistic productions. As the ongoing Catalan

\begin{tabular}{lccccc} 
& Estimate & Std. Error & $t$-value & $p$-value & \\
\hline (Intercept) & 1.693 & $5.892 \mathrm{e}-02$ & 28.730 & $2 \mathrm{e}-16$ & $* * *$ \\
Spanish & $1.201 \mathrm{e}-01$ & $1.341 \mathrm{e}-02$ & 8.959 & $2 \mathrm{e}-16$ & $* * *$ \\
Younger & $7.617 \mathrm{e}-03$ & $7.546 \mathrm{e}-02$ & 0.101 & 0.921 & \\
/e/ & $9.241 \mathrm{e}-02$ & $2.058 \mathrm{e}-02$ & 4.490 & $2.15 \mathrm{e}-5$ & $* * *$ \\
Spanish: Younger & $-5.335 \mathrm{e}-02$ & $1.748 \mathrm{e}-02$ & -3.052 & 0.002317 & $* *$ \\
Spanish: /e/ & $-6.718 \mathrm{e}-02$ & $1.896 \mathrm{e}-02$ & -3.544 & $4.08 \mathrm{e}-4$ & $* * *$ \\
Younger: /e/ & $-2.710 \mathrm{e}-02$ & $1.748 \mathrm{e}-02$ & -1.551 & 0.1212 & \\
Spanish: Younger: /e/ & $1.725 \mathrm{e}-02$ & $2.472 \mathrm{e}-02$ & 0.698 & 0.485 & \\
\hline
\end{tabular}

Table 3. Coefficients for the mixed effects linear regression model predicting F2. The intercept is the Catalan $/ \varepsilon /$ productions by older speakers. 


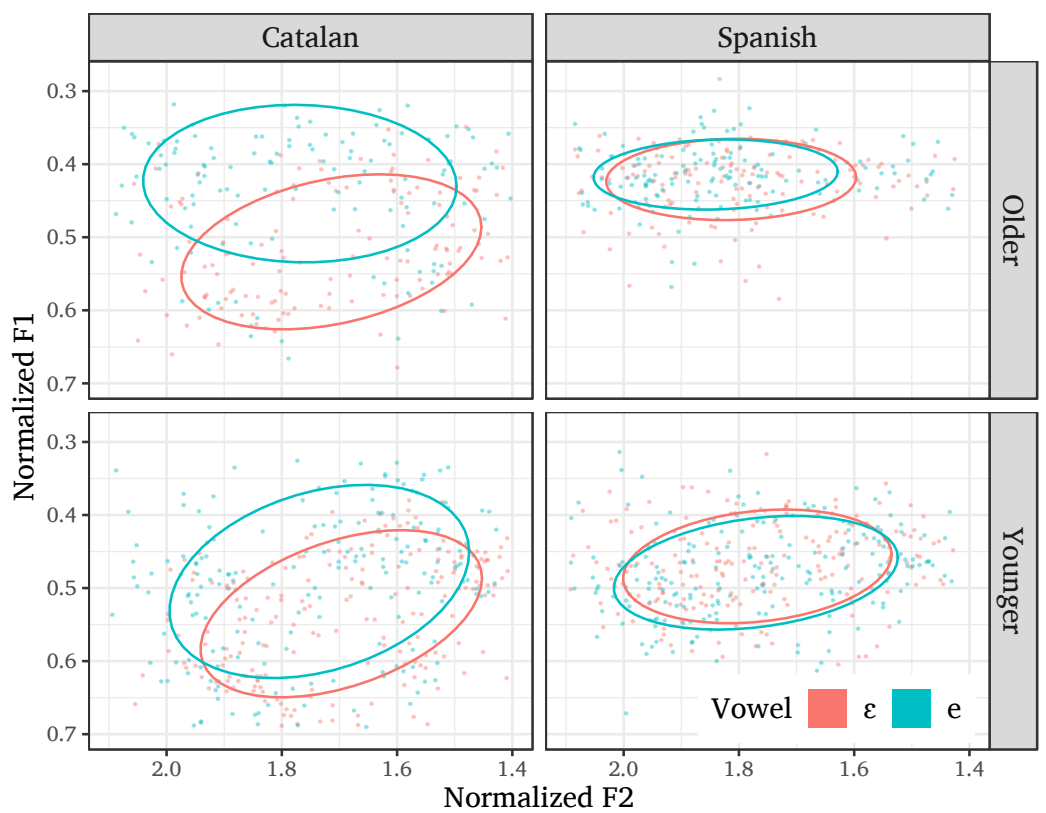

Figure 2. Vowel space plots of Catalan and Spanish mid front vowel productions across the two generations of speakers, where Spanish /e/ productions are plotted according to the vowel in the Catalan cognate.

mid front vowel merger in Barcelona (see Bosch \& Ramon-Casas 2011; Cortés et al. 2019; inter alia) would produce a very diffuse merged category along the F1 axis, a similar diffusion in Spanish /e/ production across F1 could suggest evidence of a Catalan contact effect in Spanish production via assimilation of Spanish productions towards Catalan vowel properties. Accordingly, an analysis of the variance of productions across age and LANGUAGE was undertaken via Levene's Test (Table 4). The main effects of AGE $(F(1,1356)=15.523, p<0.01)$ and LANGUAGE $(F(1,1356)=213.483, p<0.01)$ were found to be significant, as well as the interaction of AGE and LANGUAGE $(F(1,1356)=7.255, p<0.01)$. Tukey post-hoc tests reveal that Catalan productions are more diffuse than Spanish productions in both generations of speakers $(p<0.01)$. Additionally, Spanish productions of younger speakers are more diffuse than those of older speakers $(p<0.01)$, whereas the diffuseness of Catalan productions over time is consistent. As expected, the diffuseness across F1 of merged Catalan productions is greater than that of Spanish, but there is possible evidence of assimilation of the Spanish category towards the merged Catalan category, as the phonetic properties of Spanish are changing among younger speakers to become more similar to those of Catalan (i.e. greater diffuseness).

A similar analysis of the variance of F2 productions across AGE and LANGUAGE was undertaken via Levene's Test (Table 5). The main effect of LANGUAGE is significant $(F(1,1356)$ $=29.702), p<0.01)$, as well as the interaction of AGE and LANGUAGE $(F(1,1356)=11.288)$, $p<0.01)$. Subsequent Tukey post-hoc tests indicate that Catalan productions are more diffuse than Spanish productions only among older speakers $(p<0.01)$. Further, the diffuseness of Spanish productions across F2 is consistent between generations, whereas the diffuseness of Catalan across F2 is reduced in the younger generation $(p<0.01)$. Therefore, there is possible 


\begin{tabular}{lcccl} 
& F value & DF & $p$-value & \\
\hline Age & 15.523 & 1 & $8.57 \mathrm{e}-5$ & $* * *$ \\
Language & 213.483 & 1 & $2 \mathrm{e}-16$ & $* * *$ \\
Age: Language & 7.255 & 1 & $7.16 \mathrm{e}-3$ & $* *$ \\
Residuals & & 1,356 & & \\
\hline
\end{tabular}

Table 4. Output of Levene's test for F1 across factors of age and language.

\begin{tabular}{lcccc} 
& F value & DF & $p$-value & \\
\hline Age & 1.306 & 1 & 0.253 & \\
Language & 29.702 & 1 & $5.98 \mathrm{e}-9$ & $* * *$ \\
Age: Language & 11.288 & 1 & $8.02 \mathrm{e}-4$ & $* * *$ \\
Residuals & & 1,356 & & \\
\hline
\end{tabular}

Table 5. Output of Levene's test for F2 across factors of age and language.

evidence of assimilation of the merged Catalan categories towards Spanish, where the phonetic property of diffuseness changes in Catalan among younger speakers so that the category becomes phonetically more similar to Spanish /e/ (i.e. less diffuse).

4. Discussion. The present study analyzed Spanish and Catalan mid front vowel production data to observe bidirectionality in the production of Spanish and Catalan mid front vowels (i.e. contact effects from both Spanish and Catalan), mainly through the process of dissimilation. The hypotheses were that mid front vowel categories would be produced differently in Spanish and Catalan to maintain a distinction, facilitated by the comparably high status and prestige attributed to both languages in Barcelona, and that this distinction might be strengthened among the younger speakers. The results of regression models predicting F1 and F2 of productions across LANGUAGE, AGE, and VOWEL indicate that these Catalan-Spanish bilinguals maintain phonetic distinction between Spanish /e/ and the Catalan mid front vowel categories in dimensions of both frontedness and height, demonstrating dissimilation. The Spanish category is produced lower than Catalan /e/ and higher than Catalan $/ \varepsilon /$, though the difference in frequency $(\mathrm{Hz})$ is smaller between Spanish /e/ and Catalan /e/. As these speakers are mostly dominant in Catalan, this is possible evidence for transfer of their Catalan /e/ to their Spanish /e/. Alternatively, the weakening contrast between the Catalan mid front vowels could lower the production of Catalan /e/, thereby decreasing the acoustic distance to Spanish /e/ and demonstrating transfer from Spanish. Production data from monolingual Spanish speakers and data from speakers with robust mid front vowel contrasts (e.g. Mallorcan Catalan) could be compared to the data presented here to further investigate whether these phonetic differences are attributed to contact effects from Catalan or Spanish, or both. Along F2, Spanish productions are more fronted than Catalan productions, especially among the older speakers. This result is a clear demonstration of dissimilation, where the categories are produced in a nonnative-like manner and acoustic distinction is maintained cross-linguistically. What remains to be seen, however, is whether these acoustic differences are perceptible and salient in addition to being statistically significant.

Although Spanish productions are statistically distinct from Catalan productions, this dis- 
tinction is not being strengthened among the younger generation of speakers; in fact, the phonetic difference between Spanish and Catalan mid front vowels across F2 is weakening in apparent-time. To determine whether other phonetic properties of the vowel categories remain distinct across the generational gap, and in acknowledgment that formant frequencies are not the sole phonetic property belonging to vowel categories, the variance within each category's F1 and F2 productions was analyzed across AGE and LANGUAGE. The significant interaction of AGE and LANGUAGE among F1 productions indicates that the variance, or diffuseness along F1, of Spanish /e/ increases in apparent-time, whereas the diffuseness of Catalan mid front vowels is consistent in apparent-time. One interpretation of this finding is that the relative diffuseness of the Catalan merged category acts as a target and motivates the increased diffuseness of Spanish /e/, resulting in cross-linguistic categories with more similar acoustic properties. The difference in mid front vowel diffuseness associated with each language can be attributed to the merger of Catalan / $/$ / and Catalan /e/, two vowels that mainly differ across F1. Consequently, the merged category is very diffuse across F1. I propose here that this diffuse nature of the Catalan mid front vowels transfers into the production of Spanish /e/ as a contact effect, yielding a wider, more diffuse category in Spanish. The pattern seen across AGE, where younger speakers show significantly more variability across F1 (i.e. yielding a wider category) than older speakers, is consistent with a change in progress. Across F2 productions, the diffuseness of the merged Catalan category decreases in apparent-time, and younger speakers produce Spanish and Catalan categories with equivalent diffuseness. This result in conjunction with the previous result suggests the bidirectional, or reciprocal, nature of the contact between the Spanish and Catalan mid front vowels. As the Catalan mid front vowel contrast weakens in Barcelona, the diffuseness across F1 of Spanish increases to become more similar to the diffuseness in Catalan, whereas the diffuseness across F2 of Catalan decreases to become more phonetically similar to Spanish (Figure 3).

Such a proposition endorses the view that Catalan contact effects may be evidenced in Spanish, a view that is consistent with the theory of contact effects and the probabilistic, rather than deterministic, effects of social and linguistic factors (Thomason 2010; Thomason \& Kaufman 1988). However, this view contradicts perspectives put forth by researchers of Barcelona Spanish, such as Arnal (2011), who maintain that Catalan contact effects in Barcelona Spanish are not improbable, but impossible. Davidson (2020) disputes this claim with evidence of
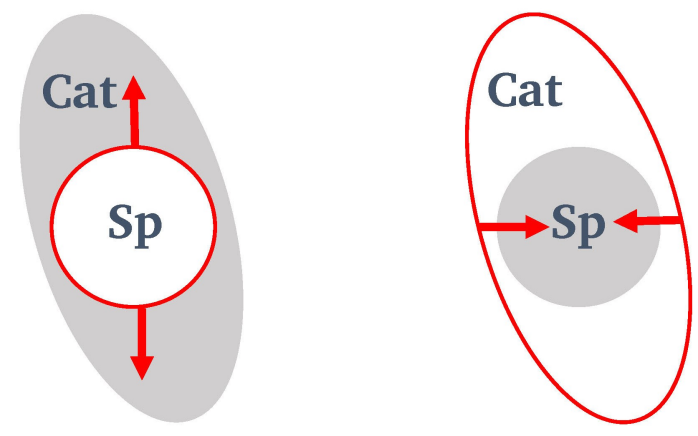

Figure 3. Visualization of bidirectional contact effects. Left: Catalan contact effects in Spanish, yielding more diffuse productions across F1. Right: Spanish contact effects in Catalan, yielding less diffuse productions across F2. 
Catalan directionality in the voicing of Barcelona Spanish intervocalic fricatives. He cites that the linguistic and social capital attributed to Catalan is equal, if not greater, than that of Spanish in Barcelona, yielding a social reality that may probabilistically favor contact effects from Catalan in Barcelona Spanish. The present study corroborates these claims and contributes a new perspective on the ways in which contact effects may be manifested. In studies of vowel production in bilingual communities, the discussion is often limited to metrics of vowel duration, formant frequencies, and patterns of vowel reduction. However, examination of characteristics of phonological categories, such as diffuseness measured by variance of formant frequencies, can provide additional sites for contact effects to be evidenced. To my knowledge, the only other example of a Spanish and Catalan vowel production study with an investigation of variance is Amengual (2011), where the variance of Catalan productions by Spanish-dominant and Catalan-dominant bilinguals is briefly compared. However, the metric of variance is used in this study to observe L1-transfer in the Catalan productions of Spanish-dominant bilinguals, rather than to observe bidirectional contact effects on both Spanish and Catalan productions.

A potential downside to this metric is that diffuseness is not identifiable from one token, but from a collection of tokens from one individual, potentially reducing the salience for the listener. Whether variance, through increasing acoustic similarity between Spanish and Catalan mid front vowels, is socially indexed can only be revealed by perception data. A lack of overt awareness of growing diffuseness of Spanish /e/ along F1 may allow for an index of shared Spanish-Catalan bilingual identity, rather than overt stereotyping of a stigmatized and accented Spanish (Davidson 2019). Similarly, Newman et al. (2008) find evidence in matched guise data for increasing linguistic cosmopolitanism in Barcelona, where Spanish varieties with influences of Catalan are valued similarly to Catalan varieties with Spanish influences across the dimension of solidarity. In addition to potential social indices accounting for growing similarity between Spanish and Catalan mid front vowel productions, the linguistic instruction received in Barcelona schools could be a contributing factor. One participant of this study mentioned during the sociolinguistic interview that students are taught in school that Spanish /e/ and Catalan /e/ are the same sound. This instruction could yield expansion of acceptable exemplars of Spanish /e/, producing greater diffuseness of Spanish /e/ across F1. As the data analyzed here were obtained from an elicited production task, it is probable that productions in less monitored speech may show even more confluence of the two categories. Furthermore, Catalan contact effects in Spanish are expected to first appear in the speech of Catalan-dominant individuals. While the participants of this study are generally more Catalan-dominant (Table 1), the younger speaker groups are more Spanish-dominant relative to the older speakers. This suggests that increased diffuseness in Spanish /e/ across F1 and the decreased diffuseness in merged Catalan mid front vowels across F2 may be phenomena that are more widespread in Barcelona, and not unique to Catalan-dominant speakers.

5. Conclusions. The results here suggest that Catalan directionality can be observed within Barcelona Spanish, specifically within the increased diffuseness of Spanish /e/ across F1. This affirms that contact effects are not unidirectional, rather, social and linguistic factors give probabilistic weight to the directionality of contact effects. Spanish contact effects in Catalan production are present in Barcelona, and are evidenced here by the ongoing merger of Catalan front mid vowels and possibly by the decreased diffuseness of F2 Catalan productions in the younger generation. However, Spanish contact effects are not the only possible outcome of 
contact in this bilingual setting, as results of Spanish /e/ diffuseness indicate. Further investigation of production by more Spanish-dominant speakers in Barcelona is still needed to incorporate the effect of language dominance in the diffuseness of Spanish /e/. In future studies, emphasis should continue to be placed on the collection of cross-linguistic data, rather than data in only one language, and metrics used to observe contact effects should take into account other features of vowel quality and statistical distributions of productions. By doing so, results may more accurately reflect the bidirectional and dynamic nature of language contact effects in situations of widespread societal bilingualism.

\section{References}

Alcover, Antoni Maria \& Francesc de Borja Moll. 2002. Diccionari català-valencià-balear.

Amengual, Mark. 2011. Spanish and Catalan in Majorca: Are there contact-induced changes in the Catalan vowel system? In Luis A. Ortiz-López (ed.), Selected proceedings of the 13th Hispanic Linguistics Symposium, 214-223. Somerville, MA: Cascadilla Proceedings Project. http://www.lingref.com/cpp/hls/13/abstract2489.html.

Amengual, Mark. 2016. The perception and production of language-specific mid-vowel contrasts: Shifting the focus to the bilingual individual in early language input conditions. International Journal of Bilingualism 20(2). 133-152. https://doi.org/10.1177/1367006914544988.

Arnal, Antoni. 2011. Linguistic changes in the Catalan spoken in Catalonia under new contact conditions. Journal of Language Contact 4(1). 5-25. https://doi.org/10.1163/187740911x558815.

Baker, Wendy \& Pavel Trofimovich. 2005. Interaction of native-and second-language vowel system(s) in early and late bilinguals. Language and Speech 48(1). 1-27. https://doi.org/10.1177/00238309050480010101.

Birdsong, David. 2018. Plasticity, variability and age in second language acquisition and bilingualism. Frontiers in Psychology 9. 1-17. https://doi.org/10.3389/fpsyg.2018.00081.

Birdsong, David, Libby M Gertken \& Mark Amengual. 2012. Bilingual Language Profile: An easy-to-use instrument to assess bilingualism. Austin: COERLL, The University of Texas.

Boersma, Paul \& David Weenink. 2019. Praat: Doing phonetics by computer.

Bosch, Laura \& Marta Ramon-Casas. 2011. Variability in vowel production by bilingual speakers: Can input properties hinder the early stabilization of contrastive categories? Journal of Phonetics 39(4). 514-526.

Carbonell, Joam \& Joaquim Llisterri. 1999. Catalan. In Handbook of the International Phonetic Association. A guide to the use of the International Phonetic Alphabet, 61-65. Cambridge, UK: Cambridge University Press.

Cook, Vivian. 1999. Going beyond the native speaker in language teaching. TESOL Quarterly 33(2). 185-209. https://doi.org/10.2307/3587717.

Cook, Vivian. 2003. Effects of the second language on the first. Bristol, UK: Multilingual Matters. https://doi.org/10.21832/9781853596346.

Cortés, Susana, Conxita Lleó \& Ariadna Benet. 2009. Gradient merging of vowels in Barcelona Catalan under the influence of Spanish. Convergence and Divergence in Lan-guage Contact Situations 185-204. https://doi.org/10.1075/hsm.8.08cor.

Cortés, Susana, Conxita Lleó \& Ariadna Benet. 2019. Weighing factors responsible for the production of the Catalan vowel $/ \varepsilon /$ versus /e/ contrast in three districts of Barcelona. International Journal of Bilingualism 23(6). 1264-1277. 
https://doi.org/10.1177/1367006918781058.

Davidson, Justin. 2019. Covert and overt attitudes towards Catalonian Spanish laterals and intervocalic fricatives. In Whitney Chappell (ed.), Recent advances in the study of Spanish sociophonetic perception, 40-83. Amsterdam: John Benjamins.

https://doi.org/10.1075/ihll.21.03dav.

Davidson, Justin. 2020. Asymmetry and directionality in Catalan-Spanish contact: Intervocalic fricatives in Barcelona and Valencia. Languages 5(4). 60.

https://doi.org/10.3390/languages5040060.

Evans, Bronwen G \& Paul Iverson. 2007. Plasticity in vowel perception and production: A study of accent change in young adults. The Journal of the Acoustical Society of America 121(6). 38143826. https://doi.org/10.1121/1.2722209.

Flege, James E. 1987. The production of "new" and "similar" phones in a foreign language: Evidence for the effect of equivalence classification. Journal of Phonetics 15(1). 47-65. https://doi.org/10.1016/s0095-4470(19)30537-6.

Flege, James E. 1995. Second language speech learning: Theory, findings, and problems. In Winifred Strange (ed.), Speech perception and linguistic experience: Issues in cross-language research, 233-277. Timonium, MD: York Press.

Flege, James E. 2002. Interactions between the native and second-language phonetic sys- tems. In Petra Burmeister, Thorsten Piske \& Andreas Rhode (eds.), An integrated view of language development: Papers in honor of Henning Wode, 217-244. Trier: Wissenschaftlicher Verlag.

Flege, James E. 2007. Language contact in bilingualism: Phonetic system interactions. Laboratory Phonology 9. 353-382.

Galindo i Solé, Mireia. 2003. Language contact phenomena in Catalonia: The influence of Catalan in spoken Castilian. In Lotfi Sayahi (ed.), Selected Proceedings of the First Workshop on Spanish Sociolinguistics, 18-29. Somerville, MA: Cascadilla Proceedings Project. http://www.lingref.com/cpp/wss/1/abstract1004.html.

Galindo i Solé, Mireia. 2006. Les llengües a l'hora del pati. usos lingüístics en les converses dels infants de primária a Catalunya: Barcelona: Universitat de Barcelona dissertation.

Grosjean, François. 1989. Neurolinguists, beware! The bilingual is not two monolinguals in one person. Brain and Language 36(1). 3-15. https://doi.org/10.1016/0093-934x(89)90048-5.

Guasch, Marc, Roger Boada, Pilar Ferré \& Rosa Sánchez-Casas. 2013. NIM: A web-based Swiss army knife to select stimuli for psycholinguistic studies. Behavior Research Methods 45(3). 765-771. https://doi.org/10.3758/s13428-012-0296-8.

Hualde, José Ignacio. 2013. Los sonidos del español: Spanish language edition. Cambridge, UK: Cambridge University Press. https://doi.org/10.1017/cbo9780511719943.

Idescat. 2011. Cens de població i habitatges (1981-2011).

Johnson, Keith. 2020. The $\Delta \mathrm{F}$ method of vocal tract length normalization for vowels. Laboratory Phonology: Journal of the Association for Laboratory Phonology 11(1). https://doi.org/10.5334/labphon.196.

Kendall, Tyler \& Valerie Fridland. 2012. Variation in perception and production of mid front vowels in the US Southern Vowel Shift. Journal of Phonetics 40(2). 289-306. https://doi.org/10.1016/j.wocn.2011.12.002.

Labov, William. 2001. Principles of language change: Social factors. Malden, MA: Blackwell . Ladefoged, Peter F. \& Keith S. Johnson. 2015. A course in phonetics. Boston, MA: Cengage. 
Lleó, Conxita, Susana Cortés \& Ariadna Benet. 2008. Contact-induced phonological changes in the Catalan spoken in Barcelona. Language Contact and Contact Languages 185-212. https://doi.org/10.1075/hsm.7.111le.

MacKay, Ian RA, James E Flege, Thorsten Piske \& Carlo Schirru. 2001. Category restructuring during second-language speech acquisition. The Journal of the Acoustical Society of America 110(1). 516-528. https://doi.org/10.1121/1.1377287.

McAuliffe, Michael, Michaela Socolof, Sarah Mihuc, Michael Wagner \& Morgan Sonderegger. 2017. Montreal Forced Aligner: Trainable text-speech alignment using Kaldi. Interspeech 2017. 498-502. https://doi.org/10.21437/interspeech.2017-1386.

Mora, Joan C \& Marianna Nadeu. 2012. L2 effects on the perception and production of a native vowel contrast in early bilinguals. International Journal of Bilingualism 16(4). 484- 500. https://doi.org/10.1177/1367006911429518.

Newman, Michael \& Mireia Trenchs-Parera. 2015. Language policies, ideologies and attitudes in Catalonia. Part 1: Reversing language shift in the twentieth century. Language and Linguistics Compass 9(7). 285-294. https://doi.org/10.1111/lnc3.12141.

Newman, Michael, Mireia Trenchs-Parera \& Shukhan Ng. 2008. Normalizing bilingualism: The effects of the Catalonian linguistic normalization policy one generation after. Journal of Sociolinguistics 12(3). 306-333. https://doi.org/10.1111/j.1467- 9841.2008.00369.x.

Pallier, Christophe, Laura Bosch \& Núria Sebastián-Gallés. 1997. A limit on behavioral plasticity in speech perception. Cognition 64(3). B9-B17.

https://doi.org/10.1016/s0010-0277(97)00030-9.

Qualtrics, LLC. 2005. Qualtrics Survey Software.

Recasens, Daniel \& Aina Espinosa. 2006. Dispersion and variability of Catalan vowels. Speech Communication 48(6). 645-666. https://doi.org/10.1016/j.specom.2008.09.002.

Riebold, John. 2013. Vowel analyzer. Praat script.

Simonet, Miquel. 2011. Production of a Catalan-specific vowel contrast by early Spanish-Catalan bilinguals. Phonetica 68(1-2). 88-110. https://doi.org/10.1159/000328847.

Tagliamonte, Sali A. 2012. Variationist sociolinguistics: Change, observation, interpretation. Hoboken, NJ: Wiley-Blackwell Publishing.

Thomason, Sara Grey \& Terrence Kaufman. 1988. Contact-induced language change: An analytic framework. Language Contact, Creolization and Genetic Linguistics 35-64.

Thomason, Sarah. 2010. Contact explanations in linguistics. In Raymond Hickey (ed.), The Handbook of language contact, 29-48. Wiley Online Library. https://doi.org/10.1002/9781444318159.ch1.

Weinreich, Uriel. 1968. Languages in contact: Findings and problems. The Hague: Mouton \& Co.

Yeni-Komshian, Grace H, James E Flege \& Serena Liu. 2000. Pronunciation proficiency in the first and second languages of Korean-English bilinguals. Bilingualism: Language and Cognition 3(2). 131-149. https://doi.org/10.1017/s1366728900000225. 